\title{
Mogamulizumab Plus EPOCH Therapy for Patients With Newly Diagnosed Aggressive Adult T-cell Leukemia/lymphoma
}

\author{
TATSURO JO ${ }^{1}$, KAORI MATSUZAKA ${ }^{2}$, HARUNA SHIOYA $^{2}$, HIROO TOMINAGA $^{2}$, \\ TAKAHIRO SAKAI ${ }^{2}$, YOHEI KANEKO ${ }^{2}$, SHIZUKA HAYASHI $^{2}$, MASATOSHI MATSUO ${ }^{1}$, \\ JUN TAGUCHI ${ }^{1}$, KUNIKO ABE ${ }^{3}$, KAZUTO SHIGEMATSU ${ }^{3}$ and RITSUKO KUBOTA-KOKETSU ${ }^{4}$ \\ ${ }^{1}$ Department of Hematology, Japanese Red Cross Nagasaki Genbaku Hospital, Nagasaki, Japan; \\ ${ }^{2}$ Department of Laboratory, Japanese Red Cross Nagasaki Genbaku Hospital, Nagasaki, Japan; \\ ${ }^{3}$ Department of Pathology, Japanese Red Cross Nagasaki Genbaku Hospital, Nagasaki, Japan; \\ ${ }^{4}$ Department of Viral Infections, Research Institute for Microbial Diseases, Osaka University, Osaka, Japan
}

\begin{abstract}
Background/Aim: Adult T-cell leukemia/lymphoma $(A T L L)$ is a relatively refractory CD4-positive peripheral T-cell lymphoma. VCAP-AMP-VECP (mLSG15) is one of the standard chemotherapeutic regimens for patients with aggressive ATLL. Mogamulizumab (moga), a monoclonal antibody for $\mathrm{C}$-C chemokine receptor 4 antigen expressed on the cell surface, has recently been poised for use as monotherapy and in combination with chemotherapy. However, to date, a significant survival benefit has not been obtained with the combination of moga $+m L S G 15$ therapy. Patients and Methods: We retrospectively analyzed 77 patients diagnosed with aggressive ATLL. Of them, 22 were treated with moga + a chemotherapy regimen comprised of etoposide, vincristine, doxorubicin, cyclophosphamide, and prednisolone (EPOCH), 16 with moga $+m L S G 15$, and 39 with chemotherapy alone. Results: A risk reduction of approximately $30 \%$ was obtained with moga + EPOCH compared with moga + mLSG15. Conclusion: The addition of moga to chemotherapy did not result in a survival benefit compared with chemotherapy alone. However, a statistically significant overall survival benefit was observed in patients with moga-induced skin disorders.
\end{abstract}

The causative agent of adult T-cell leukemia/lymphoma (ATLL) is the retrovirus human T-cell lymphotropic virus type 1 (HTLV-1), which infects CD4-positive T-lymphocytes

This article is freely accessible online.

Correspondence to: Tatsuro Jo, MD, Ph.D., Department of Hematology, Japanese Red Cross, Nagasaki Genbaku Hospital, Morimachi 3-15, Nagasaki 852-8511, Japan. Tel: +81 958471511, Fax: +81 958419613, e-mail: firetj@nagasaki-med.jrc.or.jp

Key Words: Adult T-cell leukemia/lymphoma, mogamulizumab, $\mathrm{EPOCH}$.
(1-3). HTLV-1 can be spread from mother to child during lactation, and the children become HTLV-1 carriers. HTLV1 can also be spread from mother-to-child during birth as well as via blood transfusions, sexual contact, or sharing needles. Approximately 3\%-5\% of carriers develop ATLL after an incubation period of several decades. There are four clinical subtypes: acute, lymphoma, smoldering, and chronic (4). Patients suffering from acute, lymphoma, and chronic ATLL with bad prognostic factors are classified as aggressive ATLL. The prognosis of aggressive ATLL remains fairly poor despite intensive chemotherapies. Allogeneic hematopoietic stem cell transplantation (allo-HSCT) was found to cure patients with aggressive ATLL who obtained a complete response (CR) with first-line chemotherapy (5).

Lenalidomide, an immunomodulating agent, and mogamulizumab (moga) have recently been poised for the treatment of aggressive ATLL $(6,7)$. However, no survival benefit has been observed in patients with aggressive ATLL treated with moga + VCAP-AMP-VECP (mLSG15) therapy, which is a standard chemotherapy treatment, compared with patients treated with mLSG15 therapy (8). Thus, the most suitable combination chemotherapy with moga must be urgently explored. Herein, we present the results of moga $+\mathrm{a}$ combination chemotherapy comprised of etoposide, vincristine, doxorubicin, cyclophosphamide, and prednisolone (EPOCH).

\section{Patients and Methods}

Patients. We retrospectively analyzed 77 aggressive ATLL patients in our hospital, who were ineligible for allo-HSCT and diagnosed after June 2000. The data cutoff date for analyses was April 30, 2020. The patients were classified into three groups according to their treatment, namely, moga $+\mathrm{EPOCH}, \operatorname{moga}+\mathrm{mLSG} 15$, and chemotherapy alone (chemo-alone group).

Treatment. The EPOCH regimen consists of continuous intravenous infusions on days $1-4$ of etoposide $\left(50 \mathrm{mg} / \mathrm{m}^{2}\right)$, vincristine $\left(0.4 \mathrm{mg} / \mathrm{m}^{2}\right)$, 
and doxorubicin $\left(10 \mathrm{mg} / \mathrm{m}^{2}\right)$, with bolus doses of cyclophosphamide (750 $\mathrm{mg} / \mathrm{m}^{2}$ on day 6) and oral prednisolone $\left(60 \mathrm{mg} / \mathrm{m}^{2}\right.$ on days $\left.1-6\right)$ (9). The mLSG15 regimen consists of the following three regimens: VCAP (vincristine, $1 \mathrm{mg} / \mathrm{m}^{2}$, maximum $2 \mathrm{mg}$; cyclophosphamide, 350 $\mathrm{mg} / \mathrm{m}^{2}$; doxorubicin, $40 \mathrm{mg} / \mathrm{m}^{2}$; and prednisolone, $40 \mathrm{mg} / \mathrm{m}^{2}$ ) on day 1; AMP (doxorubicin, $30 \mathrm{mg} / \mathrm{m}^{2}$; ranimustine, $60 \mathrm{mg} / \mathrm{m}^{2}$; and prednisolone, $40 \mathrm{mg} / \mathrm{m}^{2}$ ) on day 8 ; and VECP (vindesine, $2.4 \mathrm{mg} / \mathrm{m}^{2}$ on day 15 ; etoposide, $100 \mathrm{mg} / \mathrm{m}^{2}$ on days $15-17$; carboplatin, 250 $\mathrm{mg} / \mathrm{m}^{2}$ on day 15 ; and prednisolone, $40 \mathrm{mg} / \mathrm{m}^{2}$ on days $\left.15-17\right)$ (8). Moga was used in combination with EPOCH or mLSG15.

In the chemo-alone group, mLSG15 monotherapy was used in $34 / 39$ patients. Three patients were treated with THP-COP therapy comprising pirarubicin $\left(30 \mathrm{mg} / \mathrm{m}^{2}\right.$ on day 1$)$, cyclophosphamide $\left(500 \mathrm{mg} / \mathrm{m}^{2}\right.$ on day 1$)$, vincristine $\left(1 \mathrm{mg} / \mathrm{m}^{2}\right.$, maximum $2 \mathrm{mg}$ on day 1 ), and prednisolone (30 mg/m $\mathrm{m}^{2}$ on days $\left.1-5\right)$ (10). The remaining two patients were treated with oral etoposide alone $(25 \mathrm{mg} /$ body on days 1-14) due to their old age (86 years old) at treatment initiation.

Granulocyte-colony stimulating factor was used as supportive therapy.

Toxicity evaluation. Toxicity was graded according to the National Cancer Institute Common Terminology Criteria for Adverse Events version $5.0(11)$.

HTLV-1 Tax-specific cytotoxic T-lymphocyte (CTL) analysis. Peripheral blood samples were drawn from each patient and CTL analyses with HTLV-1 Tax-specific tetramer without any stimulation. The analyses were performed by SRL (Tokyo, Japan).

Statement of ethics. The study was approved (approval number: 294) by the Japanese Red Cross Nagasaki Genbaku Hospital and was conducted in accordance with the Declaration of Helsinki.

Statistical analysis. The Kaplan-Meier method was used to estimate patient survival, and the difference in survival between the groups was analyzed using the log-rank test. Overall survival (OS) was calculated as the time between the date of the first treatment administration to the date of last follow-up or death. Unpaired $t$ tests and one-way analyses of variance were conducted to compare the sex, age, ATLL subtype, and existence of moga-induced skin disorders between the patient groups. Chi-square tests were conducted to analyze the statistical difference between adverse events. Differences among the results of comparative tests were considered significant if two-sided $p$-values were $<0.05$. All analyses were performed using GraphPad Prism 6 software (GraphPad Software, San Diego, CA, USA).

\section{Results}

Patient characteristics. The three treatment groups comprised 22 patients in the moga + EPOCH group, 16 in the moga + mLSG15 group, and 39 in the chemo-alone group (Table I). The patients in the moga $+\mathrm{EPOCH}$ group were significantly older than those in the moga + mLSG15 group and the chemo-alone group at treatment initiation $(p=0.0002)$. There was no significant difference in sex and disease subtype between the groups. Moga-induced skin disorders, such as rash and erythema, were observed in 13/22 $(59 \%)$ patients in the moga $+\mathrm{EPOCH}$ group and 8/16 (50\%)
Table I. Characteristics of aggressive adult T-cell leukemia/lymphoma patients according to the three treatment groups.

\begin{tabular}{lccc}
\hline Variable & $\begin{array}{c}\text { Moga }+ \\
\text { EPOCH } \\
(\mathrm{n}=22)\end{array}$ & $\begin{array}{c}\text { Moga }+ \\
\text { mLSG15 } \\
(\mathrm{n}=16)\end{array}$ & $\begin{array}{c}\text { Chemo- } \\
\text { alone } \\
(\mathrm{n}=39)\end{array}$ \\
\hline $\begin{array}{l}\text { Gender } \\
\quad \text { Male }\end{array}$ & 9 & 9 & 20 \\
$\quad \begin{array}{l}\text { Female } \\
\text { *Age at treatment }\end{array}$ & 13 & 7 & 19 \\
$\begin{array}{l}\text { initiation, years } \\
\text { (median) }\end{array}$ & $62-90(77)$ & $45-87(65.5)$ & $42-86(65)$ \\
$\begin{array}{l}\text { Subtype } \\
\text { Acute }\end{array}$ & & & \\
$\quad \begin{array}{l}\text { Lymphoma } \\
\text { Moga-induced skin disorders } \\
+\end{array}$ & 18 & 12 & 25 \\
$\quad-\quad$ & 4 & 14 \\
$\quad \begin{array}{l}\text { Date of treatment } \\
\text { initiation }\end{array}$ & 9 & 8 & Not applicable \\
\hline
\end{tabular}

moga: Mogamulizumab; mLSG15: VCAP-AMP-VECP therapy; chemo: chemotherapy. *The age at treatment initiation for the moga $+\mathrm{EPOCH}$ group was significantly older than the moga + mLSG15 group and the chemo-alone group $(p=0.0002)$.

patients in the moga + mLSG15 group, but the difference was not statistically significant (Table I).

Survival analyses. Figure 1 shows the OS of the three groups. There was no significant difference $(p=0.3453)$ between the moga + EPOCH and the moga + mLSG15 groups, but a risk reduction of approximately 30\% was observed in the moga $+\mathrm{EPOCH}$ group [hazard ratio $(\mathrm{HR})=0.7047,95 \%$ confidence interval $(\mathrm{CI})=0.3264-1.469]$, although the patients treated with moga $+\mathrm{EPOCH}$ were significantly older than those treated with moga + mLSG15 (Table I). However, no OS benefit was observed in the moga + EPOCH group compared with the chemo-alone group $(p=0.6962, \mathrm{HR}=0.8789,95 \% \mathrm{CI}=0.4581-1.678)$. Moreover, the OS of the moga-mLSG15 group tended to be rather short compared with that of the chemo-alone group $(p=0.6317$, $\mathrm{HR}=1.171,95 \% \mathrm{CI}=0.6026-2.324)$.

Figure 2 shows the OS of aggressive ATLL patients with and without moga-induced skin disorders compared with those treated with chemotherapy alone. The OS of the mogainduced skin disorders group was significantly greater than that of the moga group without skin disorders $(p=0.0142$, $\mathrm{HR}=0.4173, \quad 95 \% \mathrm{CI}=0.1560-0.7927) . \quad$ No statistical significance was observed $(p=0.3550)$ in a comparison of the moga-induced skin disorders group with the chemo-alone group, but a risk reduction of approximately 26\% was observed in the moga-induced skin disorder-positive group ( $\mathrm{HR}=0.7388,95 \% \mathrm{CI}=0.3868-1.392)$. 


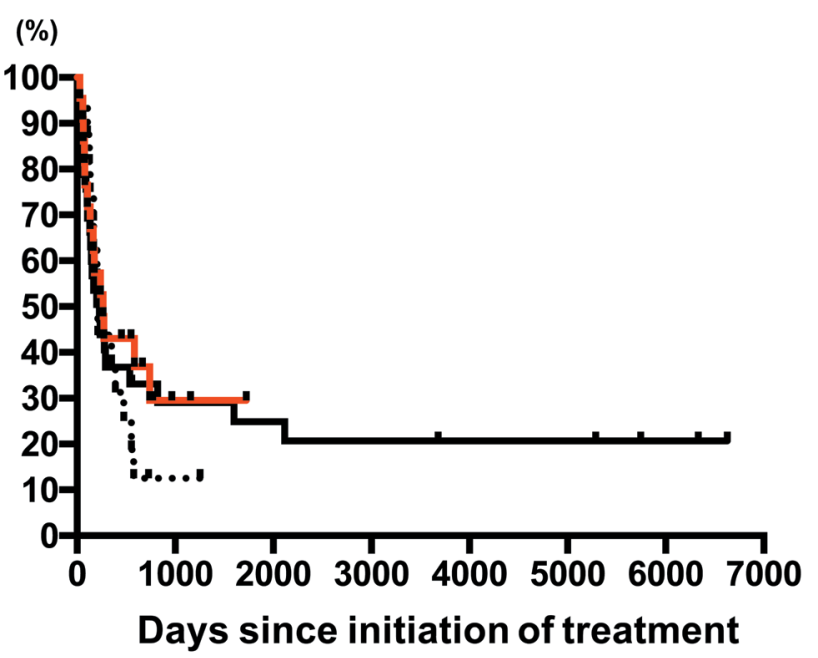

Figure 1. Overall survival of aggressive ATLL patients treated with moga + EPOCH, moga + mLSG15, and chemo-alone. Red line: moga + EPOCH group $(n=22)$, black dotted line: moga + mLSG15 group $(n=16)$, black solid line: chemo-alone group $(n=39)$. In the chemo-alone group, 34/39 patients were treated with $\mathrm{mLSG} 15$, three with THP-COP therapy, two with oral etoposide-monotherapy.

Analysis of HTLV-1 Tax-specific CTLs. Figure 3 shows representative data of the percentage elevation of Taxspecific CTLs. A systemic rash was observed after the third cycle of moga $+\mathrm{EPOCH}$ therapy in a patient with aggressive disease. An elevation of Tax-specific CTLs was observed after the rash occurred, and the disease state was controlled, as shown by a reduction in the lactate dehydrogenase (LDH) and soluble interleukin 2 receptor (sIL-2R) values. Such cases were observed in both moga-including therapy groups.

Hematoxylin-eosin (HE) and immunohistochemical staining of moga-induced skin disorders. Figure 4 shows representative data from a skin biopsy of moga-induced skin disorder by $\mathrm{HE}$ and immunohistochemical staining. Spongiosis, intracellular edema, vascular endothelium swelling, and perivascular infiltration were observed (Figure 4, A-C). Immunohistochemical staining showed that the main infiltrates were CD8positive T-cells (Figure 4, D and E).

Safety outcomes. Table II summarizes the adverse events in patients treated with moga-EPOCH and moga-mLSG15. There was no significant difference in hematologic adverse events (anemia, thrombocytopenia, lymphopenia, and neutropenia) between the two groups. Grade 3 febrile neutropenia was observed in $9 / 22(41 \%)$ patients in the moga-EPOCH group and 3/16 (19\%) patients in the mogamLSG15 group. Moga-induced skin disorders were observed in both groups, but this was not statistically significant $(p=0.7691)$.

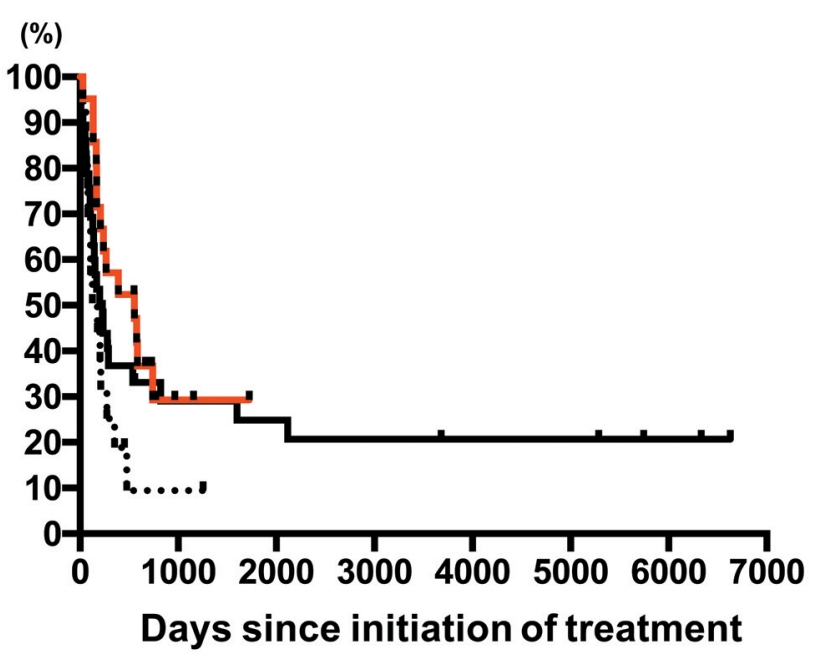

Figure 2. Overall survival of aggressive ATLL patients with and without moga-induced skin disorders and treated with chemotherapy alone. Red line: moga-induced skin disorders-positive group $(n=23)$, black dotted line: moga-induced skin disorders-negative group $(n=15)$, black solid line: chemo-alone group $(n=39)$.

\section{Discussion}

Over $90 \%$ of ATLL cells express C-C chemokine receptor 4 antigen (CCR4) on their cell surface, and CCR4 expression was thought to be closely related to the skin invasion of ATLL cells and the unfavorable prognosis of $\operatorname{ATLL}(12,13)$. ATLL cells form tumor lesions not only in the skin but also in other organs with a rich blood supply, like muscles (14). Such extraordinary organ involvement of ATLL cells, as in lymphoma, might be linked to treatment difficulties. However, the association between a high frequency of CCR4 expression and ATLL led to the production of moga, a CCR4-targeted therapeutic (7). However, the combination of moga and mLSG15 therapy did not show a survival benefit compared with mLSG15 therapy alone in newly diagnosed aggressive ATLL cases, contrary to our expectations (8). These results could indicate that we have yet to discover a more effective method to utilize moga in combination with chemotherapy. Therefore, it is meaningful to seek another chemotherapy regimen to combine with moga to elucidate the potential of the drug as an antibody. Although mLSG15 therapy remains one of the effective therapeutic options, it forces patients to be hospitalized for 3-4 weeks per treatment cycle. In comparison, the administration of EPOCH therapy, which was originally developed for relapsed or refractory non-Hodgkin lymphoma, lasts 6 days. Therefore, we retrospectively analyzed the effectiveness and toxicities of EPOCH therapy in combination with moga by comparing them with those of moga + mLSG15 and chemotherapy alone. 

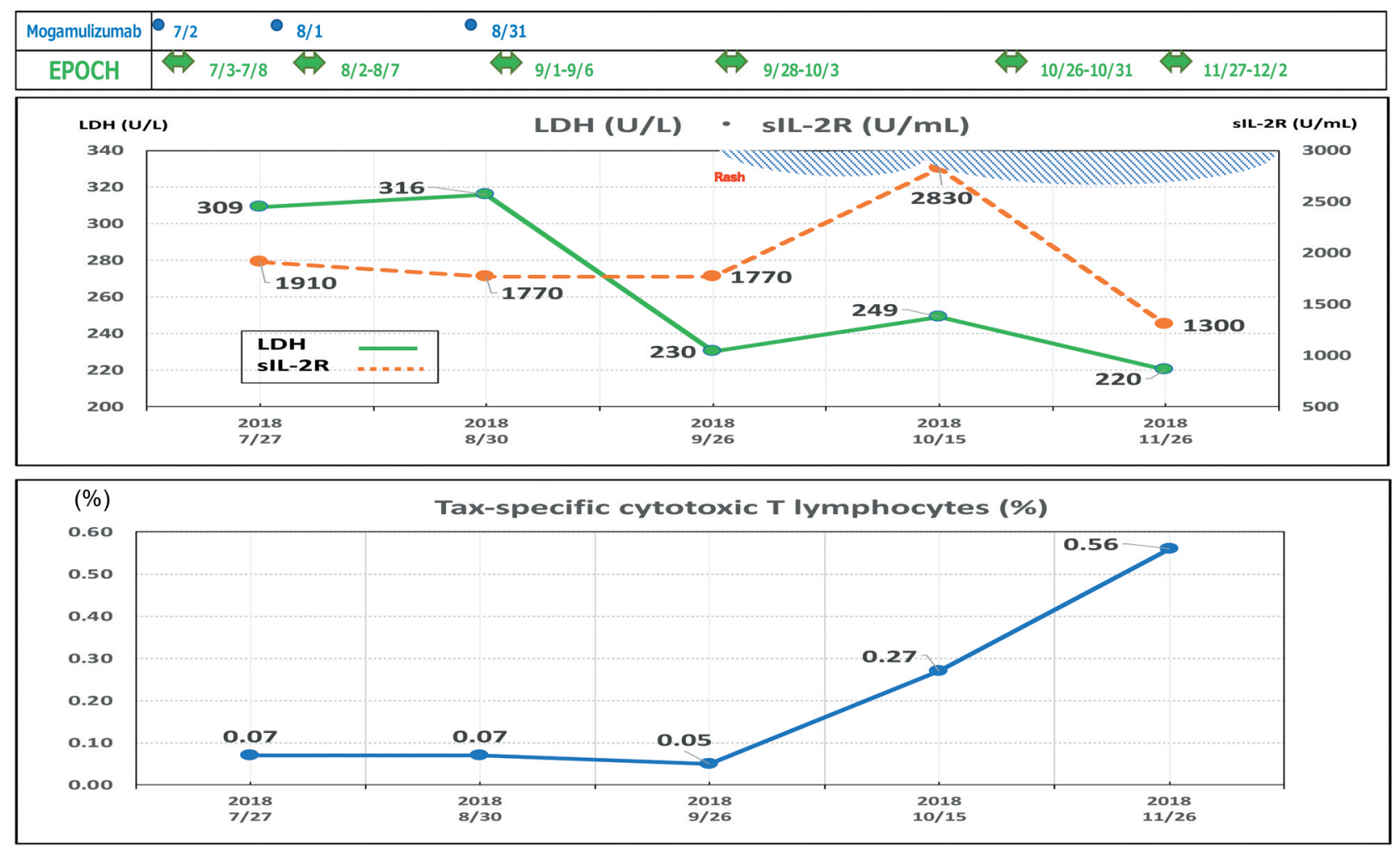

Figure 3. Changes in the levels of lactate dehydrogenase $(L D H)$ and soluble interleukin 2 receptor $($ sIL-2R) as well as the number of human T-cell lymphotropic virus type 1 (HTLV-1) Tax-specific cytotoxic T-lymphocytes (CTLs) in an aggressive ATLL patient. Green line: LDH values, orange line: sIL-2R values, blue line: HTLV-1 Tax-specific CTL values. The shaded area indicates the period of moga-induced skin disorder.

Table II. Adverse events in patients treated with moga-EPOCH (n=22) and moga-mLSG15 ( $n=16)$.

\begin{tabular}{|c|c|c|c|c|c|c|c|}
\hline \multirow[t]{2}{*}{ Event } & \multicolumn{4}{|c|}{ Grade } & \multirow{2}{*}{$\begin{array}{l}\text { All grades } \\
\text { n }(\%)\end{array}$} & \multirow{2}{*}{$\begin{array}{c}\text { Grades } 3 / 4 \\
\mathrm{n}(\%)\end{array}$} & \multirow[t]{2}{*}{$p$-Value } \\
\hline & 1 & 2 & 3 & 4 & & & \\
\hline \multicolumn{8}{|l|}{ Anemia } \\
\hline Moga-EPOCH & 4 & 7 & 5 & 0 & $16(73)$ & $5(23)$ & \multirow[t]{2}{*}{0.4000} \\
\hline Moga-mLSG15 & 1 & 8 & 3 & 0 & $12(75)$ & $3(19)$ & \\
\hline \multicolumn{8}{|l|}{ Thrombocytopenia } \\
\hline Moga-EPOCH & 1 & 2 & 7 & 5 & $15(68)$ & $12(55)$ & \multirow[t]{2}{*}{0.4210} \\
\hline Moga-mLSG15 & 0 & 3 & 4 & 1 & $8(20)$ & $5(31)$ & \\
\hline \multicolumn{8}{|l|}{ Lymphopenia } \\
\hline Moga-EPOCH & 0 & 1 & 9 & 12 & $22(100)$ & $21(95)$ & \multirow[t]{2}{*}{0.3631} \\
\hline Moga-mLSG15 & 0 & 0 & 4 & 12 & $16(100)$ & $16(100)$ & \\
\hline \multicolumn{8}{|l|}{ Neutropenia } \\
\hline Moga-EPOCH & 0 & 1 & 4 & 15 & $20(91)$ & $19(86)$ & \multirow[t]{2}{*}{0.2297} \\
\hline Moga-mLSG15 & 0 & 3 & 4 & 7 & $14(88)$ & $11(69)$ & \\
\hline \multicolumn{8}{|l|}{ Febrile neutropenia } \\
\hline Moga-EPOCH & 0 & 0 & 9 & 0 & $9(41)$ & $9(41)$ & \multirow[t]{2}{*}{ Not calculated } \\
\hline Moga-mLSG15 & 0 & 0 & 3 & 0 & $3(19)$ & $3(19)$ & \\
\hline \multicolumn{8}{|c|}{ Moga-induced skin disorders } \\
\hline Moga-EPOCH & 2 & 5 & 6 & 0 & $13(59)$ & $6(27)$ & \multirow[t]{2}{*}{0.7691} \\
\hline Moga-mLSG15 & 2 & 2 & 4 & 0 & $8(50)$ & $4(25)$ & \\
\hline
\end{tabular}

Moga: Mogamulizumab; mLSG15: VCAP-AMP-VECP therapy. 


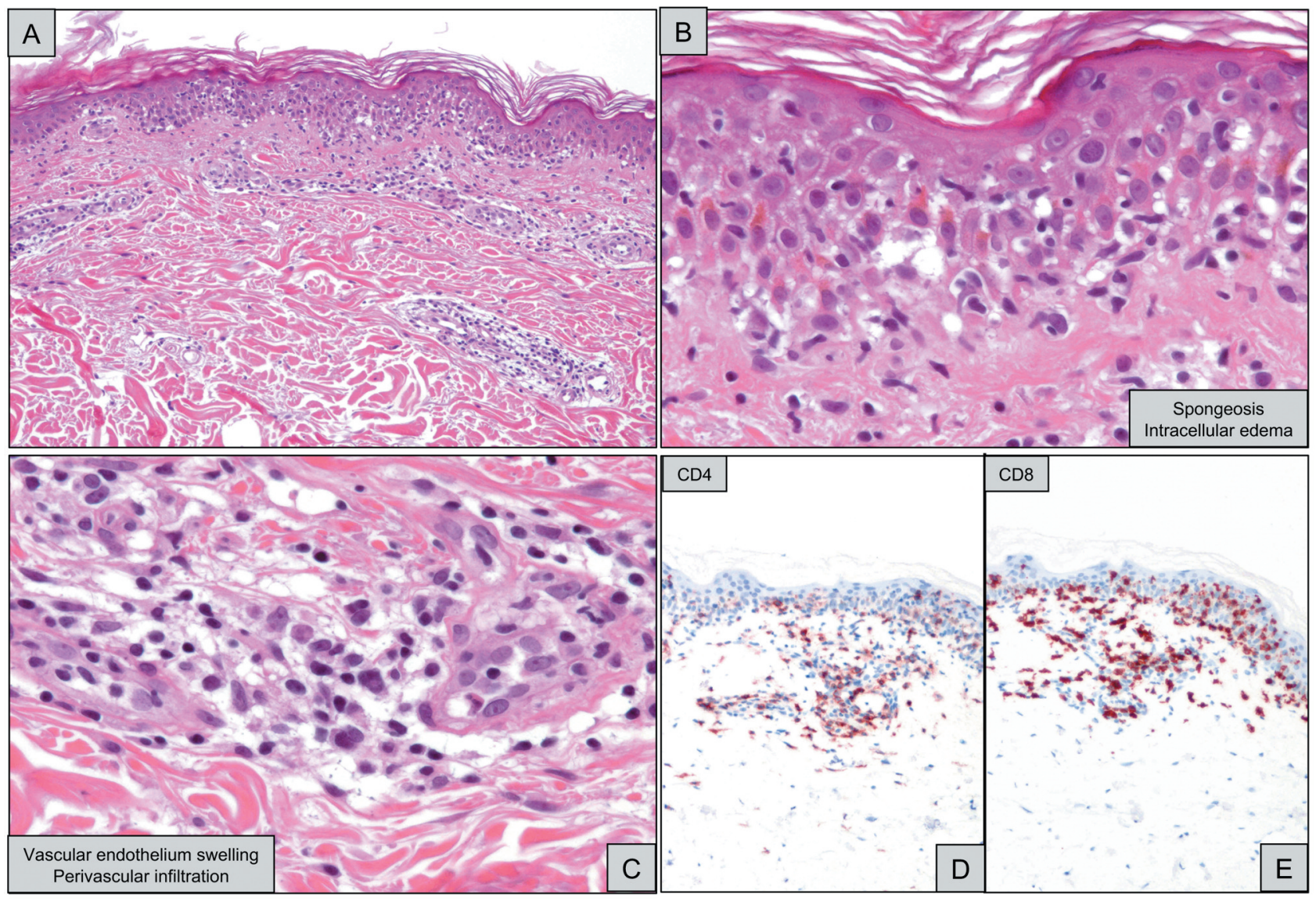

Figure 4. Mogamulizumab-induced skin disorder. Skin biopsies of the moga-induced skin disorders were analysed by hematoxylin-eosin (HE) and immunohistochemical staining. A representative case is shown. A: HE (x100 magnification), B and C: HE (x400), D:CD4 (x100), E: CD8 ( $\times 100)$.

The primary objective of this study was to ascertain whether moga-EPOCH treatment surpassed moga-mLSG15 in terms of OS. The results were satisfactory in this regard (Figure 1). The OS of the moga-EPOCH group was longer than that of the moga-mLSG15 group ( $p=0.3453$, $\mathrm{HR}=0.7047,95 \% \mathrm{CI}=0.3264-1.469)$. As for adverse events, no additional safety concerns were observed in the mogaEPOCH group compared with the moga-mLSG15 group (Table II). However, no survival benefit was observed when comparing the moga-EPOCH and chemo-alone groups $(p=0.6962, \mathrm{HR}=0.8789,95 \% \mathrm{CI}=0.4581-1.678)$. Furthermore, the OS of the moga-mLSG15 group appeared inferior to that of the chemo-alone group, which included 34/39 (87\%) patients treated with mLSG15 $(p=0.6317, \mathrm{HR}=1.171$, $95 \% \mathrm{CI}=0.6026-2.324)$. Although it is difficult to reach a definitive conclusion due to the limitations of the small sample size and the retrospective type of this study, these results suggest that the addition of moga to chemotherapy may not result in a survival benefit, at least in these settings. Our results were consistent with the previously reported non- superiority of moga-mLSG15 compared with mLSG15 alone in newly diagnosed aggressive ATLL patients (8). However, survival benefits in patients with moga-induced skin disorders were observed (Figure 2). Skin biopsies of moga-induced skin disorders revealed the infiltration of CD3- and CD8-positive CTLs in these lesions, and it is speculated that CTLs against ATLL cells might be activated in patients with moga-induced skin disorders (15). HTLV-1 Tax-specific CTLs were detected in long-term survivors treated with allo-HSCT (16). Further, we reported that HTLV-1 Tax-specific CTLs were maintained for an extended period in several patients treated with mLSG15 alone (17). In many cases of moga + chemotherapy, Tax-specific CTLs were detected after the occurrence of moga-induced skin disorders (Figure 3 shows a representative case). CD8-positive T-cells were the main infiltrates of such moga-induced skin disorders (Figure 4 shows a representative case). These results indicate that the elevation and maintenance of CTLs against ATLL cells, such as Tax-specific CTLs, may be essential for the long-term survival of aggressive ATLL patients. 
Moga was engineered to exert a highly potent antibodydependent cellular cytotoxicity via defucosylation technology (7). We suggest, that although moga can activate natural killer cells, it may be unable to sufficiently induce CTLs against ATLL cells. Furthermore, conventional chemotherapy drugs, such as doxorubicin, vincristine, and cyclophosphamide, may weaken immune activation in response to moga. Therefore, it would be better to allow an interval between chemotherapy and moga administration so that the patients can recover from chemotherapy-induced immunosuppression. Moga-induced skin disorders were recognized in patients treated with mogaEPOCH and in those treated with moga-mLSG15. These results suggest that the combination chemotherapy regimen might be irrelevant for inducing moga-induced skin disorders and for the elevation of the Tax-specific CTLs in patients treated with moga. Although there was no survival benefit, the rate of CR was found to be higher in the moga-mLSG15 group compared with the mLSG15-alone group in newly diagnosed aggressive ATLL patients in the previously mentioned phase II study (8). Collectively, we think that a possible treatment option could be moga + chemotherapy, such as EPOCH. We suggest the administration of 1-2 cycles at first, and if sufficient tumor reduction is achieved, such as CR or partial response, chemotherapy could be administered without moga for another 2-3 cycles, followed by several cycles of moga monotherapy to induce CTLs against ATLL cells.

In summary, improved OS was observed more frequently in the moga + EPOCH group than in the moga + mLSG15 group. However, to date, moga + chemotherapy has not shown a significant impact on OS for newly diagnosed aggressive ATLL patients in non-HSCT settings, except for patients with moga-induced skin disorders. Elevation of the Tax-specific CTL percentage was observed in some patients with mogainduced skin disorders. We have previously reported that several aggressive ATLL patients who obtained long-time survival using chemotherapy alone had maintained Taxspecific CTLs for extended periods (17). Therefore, it might be necessary to induce, up-regulate, and maintain ATLLspecific CTLs to obtain long-time survival. Moga is useful, but insufficient, for inducing such CTLs. To date, no effective method is available to activate an ATLL-specific cellular immune response. Further studies are urgently required to establish effective methods for attaining ATLL-specific CTLs.

\section{Conflicts of Interest}

The Authors declare that they have no conflicts of interest in relation to this study.

\section{Authors' Contributions}

TJ designed the work and acquired, analyzed, and interpreted data, as well as wrote this manuscript. KM, HS, HT, TS, YK, SH, MM,
JT, KA, and KS conducted the acquisition and the analysis of data. RKK discussed the conception of this manuscript.

\section{Acknowledgements}

The Authors thank Ms. Riyo Matsumoto for editing this manuscript.

\section{References}

1 Poiesz BJ, Ruscetti FW, Gazdar AF, Bunn PA, Minna JD and Gallo RC: Detection and isolation of type $\mathrm{C}$ retrovirus particles from fresh and cultured lymphocytes of a patient with cutaneous T-cell lymphoma. Proc Natl Acad Sci USA 77(12): 7415-7419, 1980. PMID: 6261256. DOI: 10.1073/pnas.77.12.7415

2 Miyoshi I, Kubonishi I, Yoshimoto S, Akagi T, Ohtsuki Y, Shiraishi Y, Nagata $\mathrm{K}$ and Hinuma Y: Type $\mathrm{C}$ virus particles in a cord T-cell line derived by co-cultivating normal human cord leukocytes and human leukaemic T-cells. Nature 294(5843): 770-771, 1981. PMID: 6275274. DOI: 10.1038/294770a0

3 Yoshida M, Seiki M, Yamaguchi $\mathrm{K}$ and Takatsuki K: Monoclonal integration of human T-cell leukemia provirus in all primary tumors of adult T-cell leukemia suggests causative role of human T-cell leukemia virus in the disease. Proc Natl Acad Sci USA 81(8): 2534-2537, 1984. PMID: 6326131. DOI: $10.1073 /$ pnas.81.8.2534

4 Shimoyama M: Diagnostic criteria and classification of clinical subtypes of adult T-cell leukemia-lymphoma. A report from the Lymphoma Study Group (1984-87). Br J Haematol 79(3): 428437, 1991. PMID: 1751370. DOI: 10.1111/j.13652141.1991.tb08051.x

5 Ishitsuka $\mathrm{K}$ and Tamura K: Human T-cell leukaemia virus type I and adult T-cell leukaemia-lymphoma. Lancet Oncol 15(11): e517-526, 2014. DOI: 10.1016/S1470-2045(14)70202-5

6 Ishida T, Fujiwara H, Nosaka K, Taira N, Abe Y, Imaizumi Y, Moriuchi Y, Jo T, Ishizawa K, Tobinai K, Tsukasaki K, Ito S, Yoshimitsu M, Ohtsuka M, Ogura M, Midorikawa S, Ruiz W and Ohtsu T: Multicenter phase II study of lenalidomide in relapsed or recurrent adult T-cell leukemia/lymphoma: ATLL002. J Clin Oncol 34(34): 4086-4093, 2016. PMID: 27621400. DOI: $10.1200 / \mathrm{JCO} .2016 .67 .7732$

7 Ishida T, Joh T, Uike N, Yamamoto K, Utsunomiya A, Yoshida S, Saburi Y, Miyamoto T, Takemoto S, Suzushima H, Tsukasaki K, Nosaka K, Fujiwara h, Ishitsuka K, Inagaki H, Ogura M, Akinaga S, Tomonaga M, Tobinai K and Ueda R: Defucosylated anti-CCR4 monoclonal antibody (KW-0761) for relapsed adult T-cell leukemia-lymphoma: A multicenter phase II study. J Clin Oncol 30(8): 837-842, 2012. PMID: 22312108. DOI: 10.1200/JCO.2011.37.3472

8 Ishida T, Jo T, Takemoto S, Suzushima H, Uozumi K, Yamamoto K, Uike N, saburi Y, Nasaka K, Utsunomiya A, Tobinai K, Fujiwara H, Ishitsuka K, Yoshida S, Taira n, Moriuchi Y, Imada $\mathrm{K}$, Miyamoto T, Akinaga S, Tomonaga M and Ueda R: Doseintensified chemotherapy alone or in combination with mogamulizumab in newly diagnosed aggressive adult T-cell leukaemia-lymphoma: a randomized phase II study. Br J Haematol 169(5): 672-682, 2015. PMID: 25733162. DOI: 10.1111/bjh. 13338

9 Wilson WH, Bryant G, Bates S, Fojo A, Wittes RE, Steinberg SM, Kohler DR, Jaffe ES, Herdt J and Cheson BD: EPOCH 
chemotherapy: toxicity and efficacy in relapse and refractory non-Hodgkin lymphoma. J Clin Oncol 11(8): 1573-1582, 1993. PMID: 7687667. DOI: 10.1200/JCO.1993.11.8.1573

10 Aoki S, Tsukada N, Nomoto N, Maruyama S, Takahashi M, Moriyama Y, Shibata A and Aizawa Y: Effect of pirarubicin for elderly patients with malignant lymphoma. J Exp Clin Cancer Res 17(4): 465-470, 1998. PMID: 10089069.

11 Common terminology criteria for adverse events (CTCAE) v5.0. Published on November 27, 2017.

12 Yoshie O, Fujisawa R, Nakayama T, Harasawa H, Tago H, Izawa D, Hieshima K, Tatsumi T, Matsushima K, Hasegawa H, Kanamaru A, Kamihira S and Yamada Y: Frequent expression of CCR4 in adult T-cell leukemia and human T-cell leukemia virus type-1-transformed T cells. Blood 99(5): 1505-1511, 2002. PMID: 11861261. DOI: 10.1182/blood.v99.5.1505

13 Ishida $\mathrm{T}$, Utsunomiya $\mathrm{A}$, Iida $\mathrm{S}$, Inagaki $\mathrm{H}$, Takatsuka $\mathrm{Y}$, Kusumoto S, Takeuchi G, Shimizu S, Ito M, Komatsu H, Wakita A, Eimoto T, Matsushima K and Ueda R: Clinical significance of CCR4 expression in adult T-cell leukemia/lymphoma: its close association with skin involvement and unfavorable outcome. Clin Cancer Res 9(10 Pt 1): 3625-3634, 2003. PMID: 14506150 .

14 Jo T and Shigematsu K: Extensive and destructive invasion of adult T-cell leukemia/lymphoma cells into systemic muscular tissues. Blood 124(10): 1690, 2014. PMID: 25328961. DOI: 10.1182/blood-2014-03-561001
15 Yonekura K, Kanzaki T, Gunshin K, Kawakami N, Takatsuka Y, Nakano N, Tokunaga M, Kubota A, Takeuchi S, Kanekura T and Utsunomiya A: Effect of anti-CCR4 monoclonal antibody (mogamulizumab) on adult T-cell leukemia-lymphoma: cutaneous adverse reactions may predict the prognosis. J Dermatol 41(3): 239-244, 2014. PMID: 24628073. DOI: $10.1111 / 1346-8136.12419$

16 Harashima N, Kurihara K, Utsunomiya A, Tanosaki R, Hanabuchi S, Masuda M, Ohashi T, Fukui F, Hasegawa A, Masuda T, Takue Y, Okamura J and Kannagi M: Graft-versus-Tax response in adult T-cell leukemia patients after hematopoietic stem cell transplantation. Cancer Res 64(1): 391-396, 2004. PMID: 14729650. DOI: $10.1158 / 0008-5472$.can-03-1452

17 Jo T, Horio K and Shigematsu K: Cytotoxic T-lymphocyte analysis of aggressive types of adult t-cell leukemia/lymphoma patients with complete remission after intensive combination chemotherapy. Blood 124(21): 1648-1648, 2014. DOI: 10.1181/blood.V124.21.1648.1648

Received May 16, 2020

Revised May 28, 2020

Accepted May 29, 2020 